\title{
Parameter Study on the Elastic Recovery Rate of Polymer Micro-channel by Rolling Embossing Process
}

\author{
Cheng Jun-fei ${ }^{1}$, Chen Xing ${ }^{1,2, *}$ \\ ${ }^{1}$ Faculty of Mechanical and Mechanics, Ningbo University, Ningbo, China \\ ${ }^{2}$ State Key Laboratory of Materials Processing and Die \& Mould Technology, Huazhong University of Science and Technology, Wuhan, China
}

Email address:

137421952@qq.com (Cheng Jun-fei),2509682316@qq.com (Chen Xing)

${ }^{*}$ Corresponding author

\section{To cite this article:}

Cheng Jun-fei, Chen Xing. Parameter Study on the Elastic Recovery Rate of Polymer Micro-channel by Rolling Embossing Process. International Journal of Materials Science and Applications. Vol. 6, No. 4, 2017, pp. 207-211. doi: 10.11648/j.ijmsa.20170604.17

Received: June 4, 2017; Accepted: July 3, 2017; Published: July 19, 2017

\begin{abstract}
To study the influence of process parameters on the elastic recovery rate of polymer micro-channel in the rolling embossing, the nonlinear finite element simulation software ABAQUS is employed. The simulated results show that the elastic recovery rate of micro-channel cross-section decreases with an increase of temperature and decrease of preloading and rolling speed. Using the orthogonal design method, the optimum temperature, preloading and rolling speed parameters can be obtained, the influence order of each factors is temperature $>$ preloading height $>$ rolling speed.
\end{abstract}

Keywords: Rolling Embossing Process, Finite Element Method, Elastic Recovery Rate, Orthogonal Test

\section{Introduction}

Nanoimprint technology has received much attention by the international nano-fabricating industry in recent years. At present, there are many kinds of micro-nano processing technology, such as optical exposure technology, electron beam lithography, microinjection molding, nanolithography etc [1]. In recent years, micro/nano processing technology has been applied in many areas [2].

However, there are many difficulties in the large area of nanoimprint, such as low production efficiency, uneven distribution of printing force and demolding difficulties. To over those problems, rolling embossing technology has been developed in recent years [3]. Due to the advantages of high productivity and low cost, it has gradually developed into a star in the nano-facturing industry. But some shortcomings appeared in the manufacturing process, such as incomplete filling, stress concentration et al, and those defects on the patterning process of the polymer has a very important impact. Yunjun Deng etc [4] designed a R 2 R hot embossing machine with an induction heating coil inside the model roll, however, the fast forming of the $\mathrm{R} 2 \mathrm{R}$ rolling embossing process limits the time for material flow and results in complicated flow behavior in the polymers. For the relationship between the mold structure and the flow profile, Yong He etc [5] used the software DEFORM to study the effect of the mold duty ratio, ratio of the mold width to the polymer thickness, concave mold, convex mold and the non-symmetric mold on the polymer flow profile, and proposed the strategy of topology optimization of mold structure to improve the polymer filling efficiency. Liu etc [6] investigated the deformation behavior of solid polymer during hot embossing process, the swallowtail deformation due to the incomplete filling occurred during the heating and applying pressure process, and reduced during the remaining temperature and pressure process, but the deformation behavior of solid polymer is not explained clearly in the rolling embossing process. Song Xiao etc [7] established a theoretical model based on the principle of electroosmosis-driven micro flow, and used COMSOL Multiphysics simulation software to reveal the feature patterns and the properties of polymer. These findings are valuable in providing a theoretical basis for electroosmosis-driven nanoimprinting, optimizing imprinting process and further enhancing the performance of the new patterning method. Lei Wan etc [8] proposed a gas-assisted hot embossing process to eliminate the swallowtail phenomenon during pattern transfer and simplify workpiece process setting, and realized the replication of high-quality pattern. With help of this method, the rate of replication greater than $95.5 \%$. However, this 
method has a long working cycle and low production efficiency in the process of large-scale embossing.

In this work, the simulation of rolling embossing process technology was carried out using a commercial FE code, ABAQUS / Standard. The specimen of amorphous polymer polycarbonate (PC) is modeled as a viscoelastic material. Using orthogonal design method, the effect of elastic recovery during roller embossing was investigated.

\section{Viscoelastic Material Model of Polymer}

It is known that the material property of amorphous polymer is strongly dependent on the temperature. When the temperature is lower than the glass transition $T_{g}$, it is glassy state, in which amorphous polymer acts like a hard and brittle solid glass. This property is regarded as the so-called viscoelasticity, as shown in This constitutive behavior can be expressed in the stress relaxation form:

$$
\sigma(\mathrm{t})=\varepsilon_{0} E(t)+\int_{0}^{t} E(t-\xi) \frac{d \varepsilon(\xi)}{d \xi} d \xi
$$

In general, the viscoelasticity model of amorphous polymer material can be expressed by the following formula:

$$
\begin{aligned}
& E(\mathrm{t})=E_{\infty}+\sum_{i=1}^{N} \exp \left(\frac{-t}{\lambda_{i}}\right) \\
& E_{0}=E(0)=E_{\infty}+\sum_{\mathrm{i}=1}^{N} E_{\mathrm{i}}
\end{aligned}
$$

where $\mathrm{E}_{0}$ is the instantaneous modulus, $\mathrm{E}_{\infty}$ is the equilibrium value of $E(t)$ after the time $t$ goes to infinity. $E_{i}$ and $\lambda_{i}$ are relaxation modulus and time constant, respectively. $\mathrm{N}$ is the number of Maxwell units. Diveded by the instantaneous modulus $\mathrm{E}_{0}$ at both sides. Eqs. (2) and (3) can be converted to a dimensionless form in Eq. (4):

$$
\begin{gathered}
\mathrm{e}(\mathrm{t})=1-\sum_{\mathrm{i}=1}^{N} \mathrm{e}_{i}\left(1-\exp \left(\frac{-t}{\lambda_{i}}\right)\right) \\
1=\mathrm{e}_{\infty}+\sum_{i=1}^{N} e_{i}
\end{gathered}
$$

In the formula $\lambda_{\mathrm{i}}=\frac{\eta_{\mathrm{i}}}{\mathrm{e}_{\mathrm{i}}}$, which $\eta_{\mathrm{i}}$ indicates viscosity.

The material deformation behavior of amorphous polymer resists is a function of temperature can be classified into three states, it means that the temperature is another property of viscoelastic polymer. Based on the time-temperature superposition principle, the effect of temperature on the material behavior is introduced through the dependence of the instantaneous stress on temperature and through a so-called reduced time concept. The express of Eq. (1) can be writtern as:

$$
\sigma(\mathrm{t}, \quad T)=\int_{-\infty}^{\mathrm{t}} E^{T_{0}}\left(\frac{\mathrm{t}-\xi}{A(T)}\right) \frac{\mathrm{d} \varepsilon(\xi)}{\mathrm{d} \xi} \mathrm{d} \xi
$$

where $A(T)$ is the time reduction factor at temperature $T$ relative to the reference temperature $\mathrm{T}_{0}$ and $\mathrm{E}^{\mathrm{T} 0}$ is the modulus at reference temperature $\mathrm{T}_{0}$.

It is essential that predict the material response at temperature $\mathrm{T}$ based on response function at a reference temperature $T_{0}$. Baed on the reduced time concept, the relationship between modulus at temperature $\mathrm{T}$ and $\mathrm{T}_{0}$ can be expressed as Eq. (7). Using the WLF equation, the time reduction factor for material can be expressed as Eq. (8) [9-10].

$$
\begin{gathered}
E\left(T_{0}, t\right)=E\left(T, t_{0} \cdot a_{T}\right) \\
\log \mathrm{a}_{T}=-\frac{C_{1}\left(T-T_{\mathrm{g}}\right)}{C_{2}+\left(T-T_{\mathrm{g}}\right)}
\end{gathered}
$$

where $\mathrm{C}_{1}$ and $\mathrm{C}_{2}$ material constant at the reference temperature $\mathrm{T}_{0}$

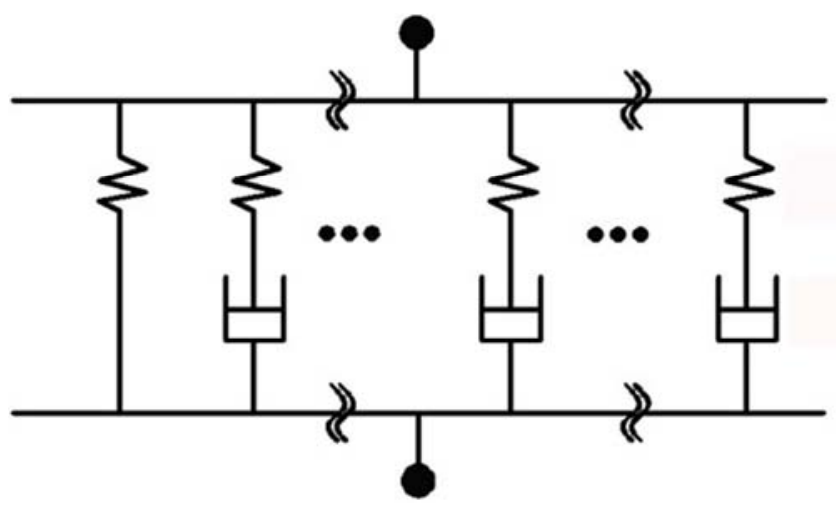

Figure 1. Generalized Maxwell model.

\section{Finite Element Methods}

A nonlinear finite element simulation software ABAQUS was employed to establish a 2-D model of driving roller with micro-arcstructure, as shown in Fig. 2.

The roller and the micro-arc structure are $100 \mathrm{~mm}$ and 0.5 $\mathrm{mm}$ in radius, respectively. In order to prevent the interaction between the two micro-arc structures on the micro-channel, the distance between the two micro-arc-structure centers is defined as six times the radius of the micro-arc. The mold made of steel is considered relatively rigid, and its deformation is rather small as compared with that of the polymer. In this paper, polymer substrate were considered to be viscoelastic material, and takes a $1.5 \mathrm{~mm} * 50 \mathrm{~mm}$. In the established finite element model, the CPE 4 RT plane strain grid is chosen, and the number of grids is 17687 . The basic parameters of polymer in Table 1 .

Several assumptions are made to simplify the analysis of 
the embossing process. Firstly, the length of the micro-channel is considered much larger than the width and depth. Secondly, the effect of gravity, friction force, surface tension is sufficiently small and can be neglected. Thirdly, it is assumed that the embossing temperature remains constant. Zero $\mathrm{x}$ and $\mathrm{y}$ displacement is applied to the bottom face, and zero $\mathrm{x}$ displacement is applied to the side face [11].

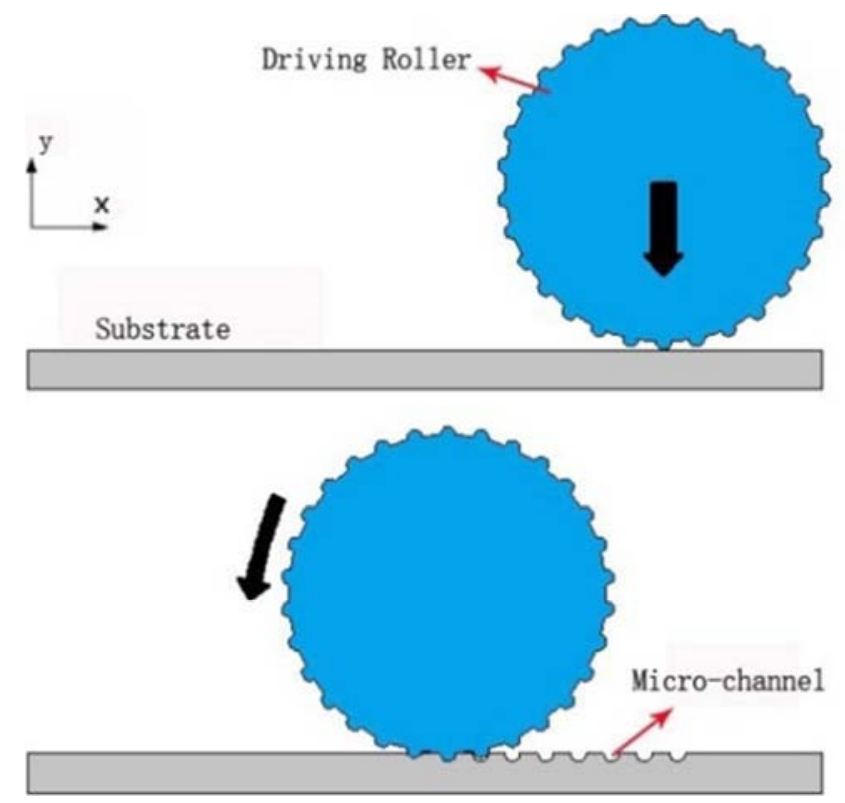

Figure 2. Conceptual drawing of the cross-section of polymer molding process.

Table 1. The basic parameters of $P C$.

\begin{tabular}{ll}
\hline Parameters & Values \\
\hline Density $\left(\mathrm{kg} / \mathrm{m}^{3}\right)$ & 1200 \\
Young's modulus $(\mathrm{MPa})$ & 2320 \\
Poisson's ratio & 0.42 \\
\hline
\end{tabular}

\section{Result and Discussion}

\subsection{Effect of Process Parameters}

When the micro-arc is separated from the substrate surface, the formed micro-channel is in the demolding stage. Elastic potential energy of the polymer is released with the decrease of the contact area between the roller and polymer material. After a period of time, the deformed material will be encounted a recovery deformation due to elastic effect, as shown in Fig 3. To measure the recovery of the micro-channel, the elastic recovery rate of the micro-channel cross-section was used as an index to study the recovery change of the micro-channel. For simplicity, it is assumed that the cross-sectional area before recovery is $\mathrm{S}$ and the cross-sectional area after recovery S1, the elastic recovery rate $(\&)$ is calculated from Eq. (9) [12-13].

$$
\&=(\mathrm{S}-\mathrm{S} 1) / \mathrm{S}
$$

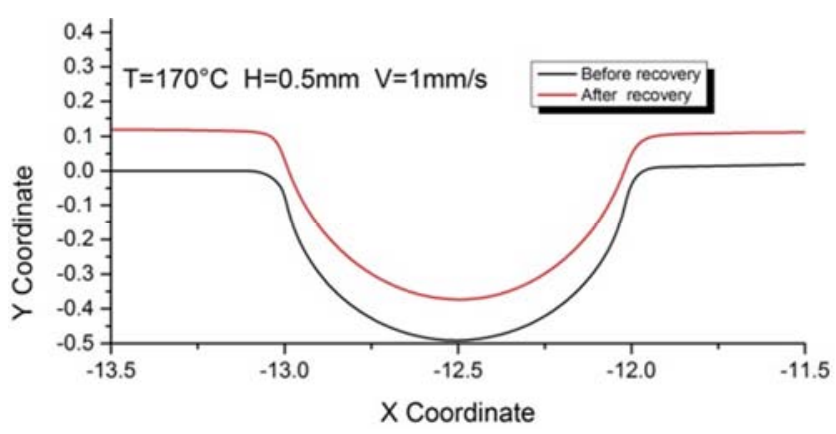

Figure 3. The micro-channel profile before/after recovery.

As the temperature, preloading height and roller speed are important factors affecting the recovery of the polymer materials [14], these three process parameters were considered and simulated in accordingly. The cross-section are of micro-channel versus process parameters before/after recovery are given in Table 2.

Table 2. Cross-section area of micro-channel before/after recovery.

\begin{tabular}{|c|c|c|c|c|c|c|}
\hline & \multicolumn{2}{|c|}{$\mathrm{T}=165^{\circ} \mathrm{C} \mathrm{H}=0.45 \mathrm{~mm} \mathrm{~V}=1 \mathrm{~mm} / \mathrm{s}$} & \multicolumn{2}{|c|}{$\mathrm{T}=170^{\circ} \mathrm{C} \mathrm{H}=0.45 \mathrm{~mm} \mathrm{~V}=1 \mathrm{~mm} / \mathrm{s}$} & \multicolumn{2}{|c|}{$\mathrm{T}=175^{\circ} \mathrm{C} \mathrm{H}=0.45 \mathrm{~mm} \mathrm{~V}=1 \mathrm{~mm} / \mathrm{s}$} \\
\hline & $\mathbf{S}$ & S 1 & $\mathbf{S}$ & S 1 & $\mathbf{S}$ & S 1 \\
\hline \multirow[t]{3}{*}{ Area $\left(\mathrm{mm}^{2}\right)$} & 0.42762 & 0.33912 & 0.39720 & 0.33397 & 0.39250 & 0.33364 \\
\hline & \multicolumn{2}{|c|}{$\mathrm{H}=0.4 \mathrm{~mm} \mathrm{~T}=170^{\circ} \mathrm{C} \mathrm{V}=1 \mathrm{~mm} / \mathrm{s}$} & \multicolumn{2}{|c|}{$\mathrm{H}=0.45 \mathrm{~mm} \mathrm{~T}=170^{\circ} \mathrm{C} \mathrm{V}=1 \mathrm{~mm} / \mathrm{s}$} & \multicolumn{2}{|c|}{$\mathrm{H}=0.5 \mathrm{~mm} \mathrm{~T}=170^{\circ} \mathrm{C} \mathrm{V}=1 \mathrm{~mm} / \mathrm{s}$} \\
\hline & $\mathrm{S}$ & S 1 & $\mathrm{~S}$ & S 1 & $\mathrm{~S}$ & S 1 \\
\hline \multirow[t]{3}{*}{ Area $\left(\mathrm{mm}^{2}\right)$} & 0.42804 & 0.37775 & 0.39720 & 0.33397 & 0.39250 & 0.30928 \\
\hline & \multicolumn{2}{|c|}{$\mathrm{V}=0.5 \mathrm{~mm} / \mathrm{s} \mathrm{H}=0.5 \mathrm{~mm} \mathrm{~T}=170^{\circ} \mathrm{C}$} & \multicolumn{2}{|c|}{$\mathrm{V}=1 \mathrm{~mm} / \mathrm{s} \mathrm{H}=0.5 \mathrm{~mm} \mathrm{~T}=170^{\circ} \mathrm{C}$} & \multicolumn{2}{|c|}{$\mathrm{V}=1.5 \mathrm{~mm} / \mathrm{s} \mathrm{H}=0.5 \mathrm{~mm} \mathrm{~T}=170^{\circ} \mathrm{C}$} \\
\hline & $\mathrm{S}$ & S 1 & $\mathrm{~S}$ & $\mathrm{~S}$ & S 1 & $\mathrm{~S}$ \\
\hline Area $\left(\mathrm{mm}^{2}\right)$ & 0.39250 & 0.31845 & 0.3925 & 0.30928 & 0.3925 & 0.30227 \\
\hline
\end{tabular}

\subsection{Analysis of Process Parameters}

To find the optimum process parameters that lead to minimum change of the elastic recovery rate, the orthogonal design method is employed [15-16].

Table 3. Orthogonal factor level table.

\begin{tabular}{llll}
\hline \multirow{2}{*}{ Level } & Factor & & \\
\cline { 2 - 4 } & Temperature A $\left({ }^{\circ} \mathbf{C}\right)$ & Preloading B $(\mathbf{m m})$ & Rolling speed C $(\mathbf{m m} / \mathbf{s})$ \\
\hline 1 & 165 & 0.4 & 0.5 \\
2 & 170 & 0.45 & 1 \\
3 & 175 & 0.5 & 1.5 \\
\hline
\end{tabular}


In experiments, as mentioned previously, three factors experiment parameters were chosen as the main factors effecting on the final quality of roll-embossing process. They are embossing temperature (A), preloading height (B) and rolling speed $(\mathrm{C})$. The factors are designed to take three levels, respectively as listed in Table 3 and test using the orthogonal array $\mathrm{L}_{9}\left(3^{4}\right)$ in Table 4.

Table 4. Test scheme and test results

\begin{tabular}{llllll}
\hline Factor & A & B & C & D & $\&$ \\
\hline 1 & 1 & 1 & 1 & 1 & 16.88 \\
2 & 1 & 2 & 2 & 2 & 20.7 \\
3 & 1 & 3 & 3 & 3 & 24.64 \\
4 & 2 & 1 & 2 & 3 & 11.75 \\
5 & 2 & 2 & 3 & 1 & 16.54 \\
6 & 2 & 3 & 1 & 2 & 18.87 \\
7 & 3 & 1 & 3 & 2 & 9.73 \\
8 & 3 & 2 & 1 & 3 & 10.87 \\
9 & 3 & 3 & 2 & 1 & 17.95 \\
$\mathrm{~F}^{1}(\mathrm{X})$ & 20.74 & 12.79 & 15.54 & & \\
$\mathrm{~F}^{2}(\mathrm{X})$ & 15.72 & 16.04 & 16.8 & & \\
$\mathrm{~F}^{3}(\mathrm{X})$ & 12.85 & 20.49 & 16.97 & & \\
$\Delta \mathrm{F}_{\mathrm{X}}$ & 7.89 & 7.7 & 1.43 & & \\
\hline
\end{tabular}

From table $4, \mathrm{~F}^{1}(\mathrm{~A})>\mathrm{F}^{2}(\mathrm{~A})>\mathrm{F}^{3}(\mathrm{~A}), \mathrm{F}^{3}(\mathrm{~B})>\mathrm{F}^{2}(\mathrm{~B})>\mathrm{F}^{1}(\mathrm{~B})$, $\left.\mathrm{F}^{3}(\mathrm{C})>\mathrm{F}^{2} \mathrm{C}\right)>\mathrm{F}^{1}(\mathrm{C})$. Obviously, factor $\mathrm{A}$ take the third level while target function is less than the other two levels, similarly, the minimized target function is achieved as the group of $A_{3} B_{1} C_{1}$ is selected. The effect on the target function is defined as difference between the maximum and minimum of $\mathrm{F}^{\mathrm{i}}(\mathrm{X})$. As shown in Table 4, $\Delta \mathrm{F}_{\mathrm{A}}=\mathrm{F}^{1}(\mathrm{~A})-\mathrm{F}^{3}(\mathrm{~A})=7.89, \Delta \mathrm{F}_{\mathrm{B}}=\mathrm{F}^{3}$ (B)- $\mathrm{F}^{1}(\mathrm{~B})=7.7, \Delta \mathrm{F}_{\mathrm{C}}=\mathrm{F}^{3}(\mathrm{C})-\mathrm{F}^{1}(\mathrm{C})=1.43$. It is observed that the $\Delta \mathrm{F}_{\mathrm{A}}>\Delta \mathrm{F}_{\mathrm{B}}>\Delta \mathrm{F}_{\mathrm{C}}$ simply the influence order of three processing parameters of embossing temperature (A), preloading height (B), rolling speed (C) in descending order.

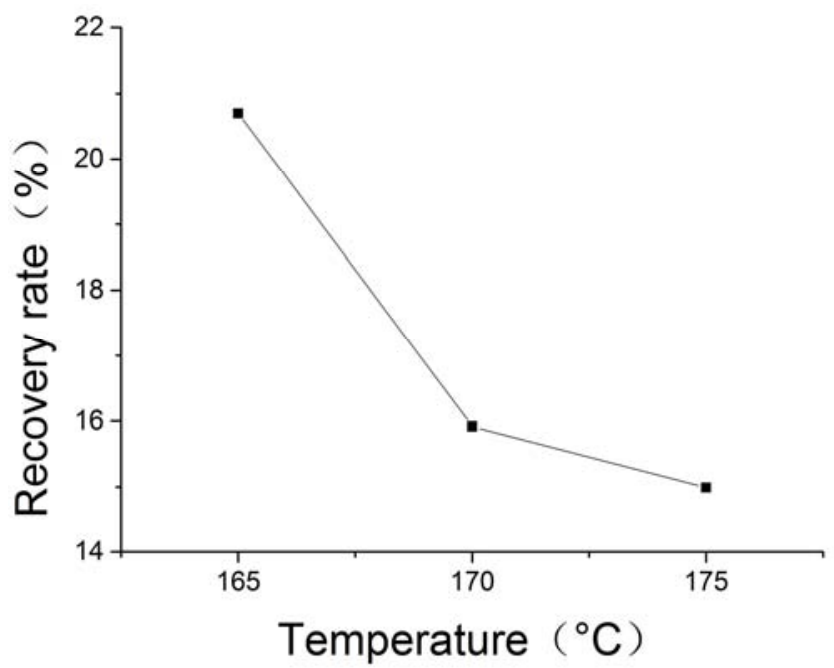

Figure 4. Effect of temperature on elastic recovery rate of micro-channel cross-section.

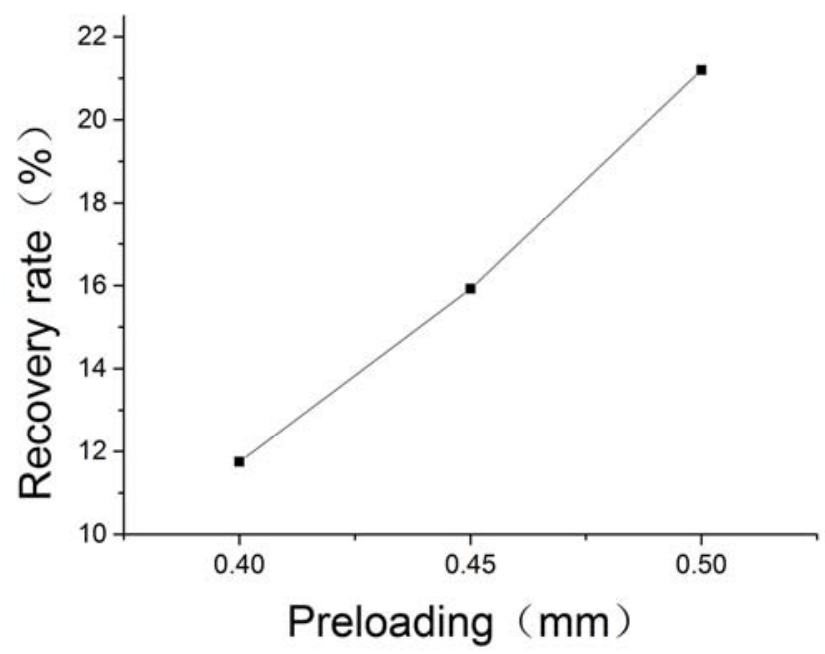

Figure 5. Effect of preloading height on elastic recovery rate of micro-channel cross-section.

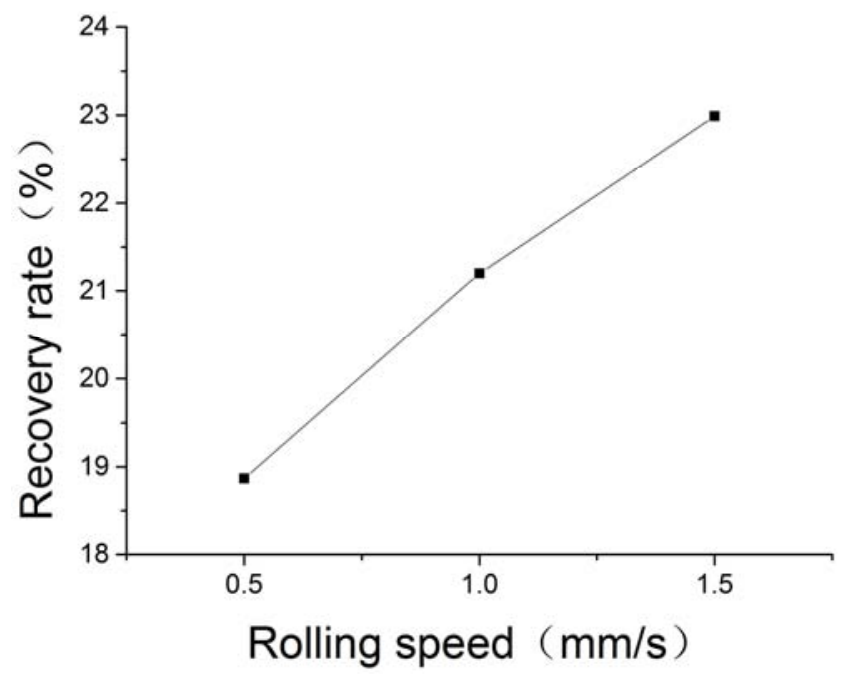

Figure 6. Effect of rolling speed on elastic recovery rate of micro-channel cross-section.

\section{Conclusion}

In this paper, the effect of process parameters on the elastic recovery rate of rolling embossing for micro-features was studied. Elastic recovery rate decreases with the increase of temperature. When the preloading height increases, the pressure on the polymer will increase, and then elastic recovery rate will increase as expected. In addition, the elastic recovery rate is enhanced as the roller speed increases. In final, using the orthogonal design method, the optimized processing parameters of temperature, preloading height and rolling speed can be obtained. The influence order of each factors is temperature $>$ preloading height $>$ rolling speed.

\section{Acknowledgements}

The Project was Supported by State Key Laboratory of Materials Processing and Die \& Mould Technology 
(P2016-21), Huazhong University of Science and Technology.

\section{References}

[1] Byron D, Gates, qiaobing Xu, Michael Stewart, et al. New Approaches to Nanofabrication: Molding, Printing, and Other Techniques [J]. American Chemical Society. 2005, 4:1171-1196.

[2] Zheng Cui. Overview of micro/nano fabrication technologies of and application [J]. Physics.2006, 35 (1):34-39.

[3] Chou S Y, Krauss P R, Zhang W, et al. Sub-10 nm imprint lithography and application [J]. Vacuum Science \& Technology.1997, 15 (16): 2897-2904.

[4] Yunjun Deng, Peiyun Yi, Linfa Peng, Xinmin Lai and Zhongqin Lin. Flow behavior of polymers during the roll-to-roll hot embossing process [J]. Journal of Micromechanics and Microengineering. 2015, 25: 1-10.

[5] Yong He, Jianzhong Fu, Zichen Chen. Study on polymer flow profile in micro hot embossing [J]. Optics and Precision Engineering. 2008, 16 (2): 270-277.

[6] C. Liu, J. M. Li, L. D. Wang. Deformation behavior of solid polymer during hot embossing process $[\mathrm{J}]$. Microelectronic Engineering. 2009, 87: 200-2007.

[7] Song Xiao, Hongbo Lan, Hongmiao Tian. Polymer flow and filling behavior for electroosmosis-driven nanoimprint lithography [J]. Science China Press. 2016, 46 (6): 615-624.
[8] Lei Wan, Ning Zhu, Xuan Li. Optimization for solid polymer microstructure replication using gas-assisted hot embossing under low pressure $[\mathrm{J}]$. International Journal of Precision Engineering and Manufacturing. 2016, 17 (8): 1067-1072.

[9] Shuhuai Lan, Hey-Jin Lee, Soo-Hun Lee. Experimental and numerical study on the viscoelastic property of polycarbonate near glass transition temperature for micro thermal imprint process [J]. Material and Design. 2009, 30: 3879-3884.

[10] Zhihong Fu, Jian Yu, Lingjiao Wei. The stress relaxation experiment and data processing analysis of polycarbonate $[\mathrm{J}]$. Plastics Industry. 2014, 42 (6): 89-92.

[11] Yiping Shi, Yurong Zhou. ABAQUS Finite element analysis esamples [M]. Beijing: Machinery Industry Press. 2006: 9-361.

[12] Haixiong Wang, Yonghu Lv, Jibin Li. Hot compression elastic recovery experiments and modeling for polymethylmethacrylate [J]. Polymeric Material Science and Engineering. 2014, 30 (9): 97-100.

[13] Peixian Xu. Rheology of polymer and application [M]. Beijing: Chemical Industry Press. 2003: 49-78.

[14] Ping Chen, Chuanlin Tang, Mingyi Liao. Structure and Properties of Polymer [M]. Beijing: Chemical Industry Press. 2013: 67-12.

[15] Chengjun Zhang. Experimental design and data processing [M]. Beijing: Chemical Industry Press. 2009: 8-62.

[16] Jian Wang, Guosheng Zhao. MATLAB Mathematical modeling and simulation [M]. Beijing: Tsinghua University Press. 2016: 20-105. 